\title{
ESPAÇOS INFRAESTRUTURAIS E VACÂNCIA: TRAÇOS DIACRÓNICOS NA FORMAÇÃO DO TERRITÓRIO METROPOLITANO DE LISBOA
}

\author{
Jỗo RAFAel SANTos ${ }^{1}$
}

\begin{abstract}
RESUMO - A formação do território metropolitano de Lisboa assentou numa complexa articulação entre o suporte fisiográfico e hidrográfico e o traçado de diversas redes infraestruturais, nomeadamente rodoviárias e ferroviárias, aterros e espaços portuários, limites e estruturas militares. Dessa articulação resultaram espaços de interface com tecidos urbanos de diversa natureza. A sua reconstituição e interpretação cartográfica permite descodificar as lógicas subjacentes aos processos de territorialização que, frequentemente, coexistem e se sobrepõem, resultantes também de alterações de uso e de racionalidade programática. Numa perspetiva diacrónica, revelam-se os traços da sua transformação: adições, justaposições, mas também persistências, subtrações e demolições. Alguns resultam fragmentados e desagregados, restos de estruturas que se perderam no esteio de mudanças tecnológicas e funcionais, descontinuados no espaço e no tempo. Espaços vacantes na atualidade, constituem áreas de oportunidade para intervenções tópicas, temporárias e imprevistas em lógicas de maior formalidade. Neste sentido, o artigo propõe uma leitura dos processos de infraestruturação do território metropolitano de Lisboa, focando-se no solo portuário e industrial e nas coroas de circulação, demarcação militar e equipamento da capital, articulando-a com o reconhecimento de espaços vacantes na atualidade. A partir desse confronto, propõe-se uma interpretação territorializada das relações entre infraestruturação e produção de vacâncias segundo uma pauta tipológica e temporal.
\end{abstract}

Palavras-chave: Infraestruturas; espaços vacantes; áreas metropolitanas; Lisboa.

ABSTRACT - INFRASTRUCTURAL SPACES AND VACANCY: DIACHRONIC TRACES IN THE SHAPING OF LISBON'S METROPOLITAN TERRITORY. Lisbon's metropolitan territory was shaped by a complex interaction between its physiographic and hydrographic features and the laying of multiple infrastructural networks, namely roads, railroads, ports and landfills, various boundaries and military facilities. This interaction

1 Professor Auxiliar e Investigador Efetivo do Centro de Investigação em Arquitetura, Urbanismo e Design (CIAUD) da Faculdade de Arquitetura da Universidade de Lisboa (FA-ULisboa), R. Sá Nogueira, 1349-063, Lisboa, Portugal. E-mail: jrs@fa.ulisboa.pt 
resulted in interfacial spaces with various types of urban fabric. The cartographic interpretation of these interfacial spaces provides insight into the logics underlying their contribution to wider territorial processes, namely those of addition, juxtaposition, persistence, subtraction and demolition. This resulted in fragmented and splintered spaces, remains of structures lost in the wake of technological and functional changes, discontinued in both in space and time. Many became today's vacant spaces; they are realms of opportunity for topical and transitional interventions, unanticipated by formal rationales. In this context, the paper provides a reading of the processes of infrastructural development of the metropolitan territory of Lisbon, focusing on port and industrial land and the belt structures defined by military perimeters, ring transportation and major urban facilities.

Keywords: Infrastructures; vacant spaces; metropolitan areas; Lisbon.

RÉSUMÉ - ESPACES URBAINS ET LIEUX VACANTS: LES ASPECTS DIACHRONIQUES DE LA FORMATION DU TERRITOIRE URBAIN DE LISBONNE. Cette formation résulte d'une articulation complexe entre sa base physiographique et hydrographique et le tracé des divers réseaux infrastructurels, surtout rodoviaires et ferroviaires, des remblais et espaces portuaires, et des limites et espaces militaires. Il en résulte des tissus urbains de natures diverses. Leur reconstitution et leur interprétation cartographique permettent de comprendre les logiques sous-jacentes aux processus de territorialisation, lesquels coexistent et se superposent fréquemment, et résultent aussi des modifications de leur usage et des normes programmatiques. Une vision temporelle révèle les aspects de cette transformation spatiale : ajouts et juxtapositions, mais aussi persistances, soustractions et démolitions. Il peut en résulter des fragments désagrégés, des restes de structures abandonnées à cause de modifications technologiques ou fonctionnelles, ou encore des discontinuités spatiales ou temporelles. Les espaces vacants actuels offrent des lieux propices aux interventions spécifiques et temporaires, difficiles à prévoir dans un cadre logique et formel. On propose donc une lecture des processus de infrastructuration du territoire métropolitain de Lisbonne, en insistant sur les espaces portuaires et industriels, sur les ceintures de circulation, sur les démarcations militaires et les monumentales de la capitale, sans oublier leur rapport avec les espaces vacants actuels. Ce qui permet d’offrir une interprétation typologique et temporelle des rapports qui lient les infrastructures aux lieux vacants.

Mots clés: Infrastructures; lieux vacants; aires métropolitaines; Lisbonne.

\section{INTRODUÇÃO}

Propõe-se, neste artigo, um reconhecimento - lido na sua dupla condição descritiva e implicitamente projetual (Dematteis, 1995, p. 15) - dos espaços infraestruturais no quadro da territorialização metropolitana de Lisboa, evidenciando e diferenciando situações de vacância - entendida como a "perda, temporária ou mais persistente, de um conjunto de usos e de valências funcionais que presidiram à sua programação e formação inicial” - a que, por fatores diversos, estão atualmente sujeitos. Para isso, salientam-se duas linhas de investigação: 1) a análise e interpretação territorial de âmbito metropolitano e, nesse âmbito, as leituras morfogénicas associadas às redes infraestruturais, 2) a identificação e 
compreensão focada nos processos de vacância de espaços infraestruturais e de áreas fragmentadas resultantes do processo de infraestruturação e a construção de alternativas programáticas e de utilização socialmente úteis.

No primeiro campo, destacam-se os contributos de Font $(1997 ; 2004)$ e de Llop (1997), na análise territorial da região metropolitana de Barcelona e na sistematização de espaços incertos e de elementos arteriais, e de Panerai (2008) e Mangin (2013) relativos à interpretação da região de Paris. Desta linha retiram-se, fundamentalmente, contributos metodológicos de sistematização de elementos (infra)estruturantes, na relação com evolução das formas de ocupação do território, utilizados em investigação anterior do autor relativa ao território metropolitano de Lisboa (Santos, 2012).

No segundo campo, destaca-se uma vasta literatura relativa a situações de desativação e abandono de espaços infraestruturais, em vários domínios. Refiram-se os relacionados com as frentes portuárias (Bruttomesso, 2001; Costa, 2006; Tölle, 2009), com os espaços intersticiais em torno de infraestruturas rodo- e ferroviárias (Barbieri, 2006; Wall, 2011) ou, num fenómeno relativamente recente, os loteamentos urbanos suspensos (Schulz-Dornburg, 2012).

Numa leitura sociotécnica, os suportes infraestruturais do território são instrumentos de coesão e de integração (Offner, 1996; Coutard, 2010; Neuman \& Smith, 2010), mas também de diferenciação e exclusão no acesso à mobilidade e a diversos serviços urbanos (Graham \& Marvin, 2001; Vormann, 2015). A introdução de infraestruturas de transporte mecanizadas no século XIX trouxe implicações profundas num espaço territorial que era caracterizado pela rugosidade topográfica e pela fricção do movimento, modelada por obstáculos, limites e (des)continuidades naturais. A cada inovação tecnológica no campo da circulação e das comunicações correspondem formas particulares de organização do território (Easterling, 1999; Herce Vallejo, Magrinyà, \& Miró, 2004), da paisagem e do espaço público (Delbere, 2010; Farhat, 2011), alterações nos sistemas de relações sociais e económicas (Urry, 2004; Disco, 2008), novos níveis e dispositivos de governação e de gestão, novas temporalidades (Delalex, 2007; Rouillard, 2007), novas referências percetivas (Appleyard, Lynch, \& Myer, 1964; Desportes, 2005), de projecto (Corboz, 1983) e de cultura e imaginário coletivos (Banham, 1971). É também pela introdução das infraestruturas de circulação, transporte e abastecimento que se abre um dos intervalos determinantes na reconfiguração do território da metrópole moderna: a dissociação morfológica entre redes e tecidos (Solà-Morales, 1995; Mangin, 2004), ou, na perspetiva de Secchi (2005), a definição de um sistema cada vez mais sofisticado de inclusões (lugares de direção económica, política e cultural, da finança ou do espetáculo) e de exclusões (cemitérios, matadouros, hospitais, quartéis, indústrias).

A espacialização das redes de circulação, comunicação e abastecimento expressa-se de formas diversas na cidade e no território, entre aderência e desconexão, entre a extrema polarização e a fratura (Choay, 1994), gerando tensões e desigualdades significativas no espaço metropolitano (Graham \& Marvin, 2001; Veltz, 2004). Coloca-se a necessidade de um reconhecimento interpretativo, que explore não só a organização das redes, mas também os espaços que as acompanham e com as quais estabelecem relações recíprocas (Solà-Morales, 1995; Smets, 2004; Donini, 2008). 
Por outro lado, no final do século XX, e perante a recomposição económica e territorial pós-industrial, as cidades ocidentais deparam-se com outras transformações, provavelmente tão incompreendidas quanto haviam sido os primeiros momentos da infraestruturação e industrialização do século XIX: os espaços resultantes da obsolescência, desativação e abandono e degradação física de complexos industriais, linhas ferroviárias, depósitos de resíduos, instalações militares, entrepostos portuários. No discurso comum, este reconhecimento tem sido percecionado de forma negativa e associado às noções de vazio, de ausência, de abandono (Corbin, 2003), ou seja, de perda de utilidade e de significado social, económico e cultural. Na literatura científica há já um corpo vasto de múltiplas designações e interpretações relativas a universos diversos e nem sempre clarificados (Berger, 2006): brownfields, derelict landscapes, terra incognita, terrains vagues, drossscapes.

Num exercício de síntese, propõe-se um quadro de sistematização tipológica em cinco perfis de situações de vacância em espaços infraestruturais:

1) espaços fragmentados: espaços resultantes da desintegração morfológica e funcional de parcelas pré-existentes, por efeito de corte associado à construção de determinada linha infraestrutural;

2) plataformas infraestruturais, em transição funcional: áreas de dimensão considerável associadas a aterros e grandes conjuntos infraestruturados, com flexibilidade de suporte de novas formas de ocupação;

3) estruturas arruinadas e recintos abandonados: espaços que perderam a utilização, mantendo-se elementos edificados e recintos sujeitos a processos de arruinamento ou demolição;

4) espaços intersticiais: espaços resultantes da sobreposição, segmentação e disjunção espacial de linhas infraestruturais e respetivas servidões;

5) espaços suspensos: espaços recentemente urbanizados/infraestruturados, com processo de edificação, comercialização e utilização suspenso devido a disrupção do mercado imobiliário.

A partir deste reconhecimento, sublinham-se quatro linhas fundamentais de argumentação face à sua condição na atualidade:

1) uma, marcada pela atitude de repulsa e classificação como patologia ou desordem do processo de produção do urbano, frequentemente invocado no discurso da regeneração urbana (Roberts \& Sykes, 2000) e das políticas europeias e nacionais de ordenamento do território (Portas, Domingues, \& Cabral, 2003; 2011; André \& Vale, 2012; Brito-Henriques, 2017);

2) uma segunda, refletindo uma maior ambivalência, entre o estranhamento e o fascínio, de que a noção de terrain vague (Solà-Morales, 1995) é paradigmática. É também nesta linha que surgem perspetivas valorizadoras da sua condição marginal, face à normativa e aos processos estabelecidos de gestão do espaço urbano, evidenciando sinais de interesse no domínio estético, ecológico e cultural (Gandy, 2013; Lokman, 2017); 
3) uma terceira, em que se reconhecem estes espaços como reflexo de um inexorável processo de evolução dinâmica do território e, em particular, da sua condição contemporânea, marcada pela urbanização extensa, heterogénea e mesclada entre-cidades (Sieverts, 1997) e pelo fenómeno do urban shrinkage (Oswald, 2003);

4) uma quarta, em que se reconhecem os espaços vacantes constituem um material de grande potencial, pela combinação da sua condição infraestrutural com um posicionamento intersticial, abrindo-se a relações múltiplas, de valorização de recursos patrimoniais e culturais, sociais e ecológicos (Pavia, 1996; 2002; Mossop, 2006; Brito-Henriques, 2017).

Desde finais da década de 1970 que várias cidades europeias e americanas foram enfrentando o desafio da sua reintegração espacial, funcional e identitária. Sobre a experiência acumulada e, entretanto, difundida praticamente por todo o mundo, produziu-se já uma significativa reflexão, compilada em diversas edições relativas a projetos especulativos ou implementados, de escalas e natureza diversas, mas sobretudo, equacionando uma utilidade valorizadora da infraestrutura para o espaço e tempo atuais (Marinoni, 2006; Rouillard, 2007; Shannon \& Smets, 2010). Num recorte mais delimitado, salientam-se os contributos centrados nas condições de temporalidade e no significado quasi arqueológico da infraestrutura (Alonzo, 2007; Lefebvre, 2007) e do seu potencial nos processos ecológicos, hidrológicos e de promoção da biodiversidade em meio urbano (Kullmann, 2011; Desimini, 2013). Projetos de escala territorial muito alargada têm vindo a demonstrar diversas possibilidades programáticas, explorando a própria construção infraestrutural do território como um processo de interesse patrimonial (Brons, 2010; IBA Fürst-Pückler-Land, 2010; Regionalverband Ruhr, 2010; Verschuure-Stuip, 2014).

Neste quadro, desenvolve-se uma identificação de processos, racionalidades e espaços significativos de suporte infraestrutural, tendo por base uma interpretação morfológica e cartográfica do território metropolitano de Lisboa (Santos, 2012). Consideram-se, nesta leitura, nomeadamente:

- a formação de solo portuário e industrial (Lisboa e Barreiro);

- a circunscrição militar e a definição de arcos de circulação e transporte (Cintura Alcântara-Xabregas e Circunvalação Algés-Sacavém);

- as linhas axiais e reticulares de abastecimento de água e energia;

- as principais redes e nós de transporte coletivo.

A interpretação deste processo estrutura-se de forma diacrónica, balizada por períodos de transformação significativa assente no cruzamento de três critérios: 1) a implementação de elementos infraestruturais relevantes para a estruturação metropolitana do território, 2) a definição de instrumentos de política, planeamento e projeto relevantes pelo alcance conceptual e repercussão concreta no território e 3) o reconhecimento de formas diferenciadas e representativas de transformação urbana e da paisagem metropolitana. Definem-se, assim, cinco intervalos temporais, balizados entre seis datas-chave:

- 1856 marca o arranque da infraestruturação ferroviária do país, a partir de Lisboa, com a inauguração do troço entre a capital e o Carregado; 
- 1891 assinala a conclusão da construção das primeiras secções do porto de Lisboa e a sua articulação ferroviária e industrial através da Linha de Cintura com as linhas radiais (Norte, Cascais, Oeste, Sul e Sueste);

- 1944 singulariza um tempo em que se promovem as bases de uma política sistematizada de obras públicas, desenvolvimento económico e modernização infraestrutural, segundo pautas de cariz centralizador e integrador de redes de âmbito nacional, repercutidas em Lisboa - cidade-metrópole do Império - num conjunto de vias automóveis, grandes equipamentos, novas afetações militares e espaços abertos de escala alargada;

- 1966 reflete um estado de redefinição da organização produtiva nacional, do aparato legislativo da urbanização e de alargamento das formas de mobilidade, de abastecimento energético e de articulação programática entre a infraestruturação de âmbito regional e o fomento industrial;

- 1995 tem como pano de fundo uma intensa pressão sobre as redes e as estruturas urbanas existentes, fruto de dinâmicas de reestruturação social e produtiva, traduzidas numa rotura entre as necessidades e a oferta das necessárias infraestruturas e equipamentos urbanos; é, por outro lado, o ano em que se lançam as bases de uma matriz metropolitana radio-concêntrica suportada pela CREL e pela CRIL;

- 2007 é marcado pelo reforço da articulação entre as margens direita e esquerda do Tejo pela melhoria das qualidades interfaciais de vários sistemas infraestruturais, a partir de oportunidades geradas pela combinação de redes de transporte coletivo com programas polarizadores (equipamento, consumo, I\&D) e com projetos de requalificação e regeneração urbana e ambiental.

\section{A PRIMEIRA ARMADURA INFRAESTRUTURAL: A CONSTITUIÇÃO DE LINHAS INFRAESTRUTURAIS E A CIRCUNSCRIÇÃO MILITAR}

O primeiro estádio de desenvolvimento de um território metropolitano é marcado pela estruturação de um conjunto inicial de linhas infraestruturais de âmbito regional e nacional, a par da delimitação de uma área perimetral em torno de Lisboa com objetivos de defesa militar (fig. 1).

A introdução do caminho-de-ferro, com o lançamento da Linha do Norte e do Leste, constitui o elemento central de reorganização das margens ribeirinhas do Tejo, de Santa Apolónia para norte. Com esta linha, introduz-se uma vocação portuária e industrial que aproveita complexos conventuais e as suas cercas, terrenos agrícolas, salinas e marinhas (Custódio, 1994a). Associa-se, assim, um entrelaçado infraestrutural constituído pela Estrada Real, pela linha do Norte, e pelo próprio rio Tejo, até então, principal meio de deslocação de pessoas e mercadorias ao longo da sua bacia hidrográfica (Alegria, 1990). A construção do Canal do Alviela, estabelece um novo patamar de abastecimento de água à capital a partir de 1880 (Costa \& Vital, 2005), com uma extensão total de $114 \mathrm{~km} \mathrm{e}$ abastecendo o Reservatório dos Barbadinhos, na zona de Santa Apolónia. Esta nova linha 
e a sua ancoragem em Lisboa reforça o sentido infraestrutural da frente oriental da cidade e, especificamente, de Santa Apolónia. É também ali que entronca a $1^{a}$ estrada de circunvalação, delimitação administrativa, militar e fiscal estabelecida em 1852 que havia determinado a evolução do território da Lisboa oitocentista (Murteira, 1999).

A $1^{a}$ circunvalação estabelece uma divisão muito clara do território urbano moderno, visível sobretudo a partir da lógica de distribuição de grandes equipamentos (cemitérios oriental e ocidental, penitenciária, matadouro, quartel de Artilharia Um). O seu perímetro acompanha de perto a orografia, tirando partido de declives acentuados como limites naturais de defesa e circunscrição. Os vales de Alcântara, a poente, e de Chelas, a ocidente, configuram não só os remates de um primeiro arco urbano, mas também espaços de transição e de oportunidade para neles se explorarem atividades de maior incomodidade para a cidade (Custódio, 1994a).

Já no último quartel do século XIX, altera-se o plano das defesas de Lisboa (Lobo, 2015), com a consolidação de um recinto de segurança entre Sacavém e Caxias e a criação do Campo Entrincheirado de Lisboa, contribuindo para o reforço de uma nova delimitação administrativa da capital (Vieira da Silva, 1940; Santana \& Sucena, 1994). Estas alterações permitem desmobilizar a primeira circunvalação, facilitando as ambições de crescimento da cidade. Neste novo enquadramento, a orografia volta a desempenhar um papel relevante, incorporando os limites naturais da Serra de Monsanto, das costeiras de Loures e do Vale do Trancão. Os limites administrativos da cidade, alargados em 1885 e estabilizados em 1896, reportam-se, em grande medida, a esta matriz fisiográfica.

No início da década de 1890 concluem-se várias infraestruturas fundamentais para a definição de um novo estádio de desenvolvimento metropolitano: as duas primeiras secções do porto de Lisboa - grande aterro entre a Rocha do Conde de Óbidos e Belém, suporte para novas unidades industriais e de infraestruturação como a fábrica de gás de Belém e a Central Tejo (Matos, 2004) -, a linha de Cascais, a linha de Cintura e o túnel e estação do Rossio. Estas obras, se entendidas de forma interdependente, constituem uma engrenagem territorial que articula as principais frentes urbanas e produtivas de Lisboa com um espaço regional mais alargado (Pinheiro, 1994; Martins, Brion, Sousa, Levy, Amorim, 1996) - uma matriz estruturadora da metrópole, baseada num conjunto de linhas radiais, assentes na ferrovia - e duplicando os antigos itinerários reais para Sintra, Cascais e Mafra - e num porto moderno, multifuncional e com espaços especializados (Custódio, 1994b). De forma discreta na paisagem urbana, mas determinante para esta engrenagem, a linha de Cintura constitui-se como arco articulador, não só das diversas linhas ferroviárias, mas também dos nós portuário-industriais de Alcântara e Xabregas. Como arco de circulação, introduz uma lógica até então praticamente ausente, de alternativa ao arco ribeirinho.

São estas as diversas linhas que, inscrevendo-se sobre um suporte territorial ainda dominantemente rústico, traçam segmentações de natureza administrativa, funcional e espacial, rompem continuidades de parcelas e azinhagas em Xabregas, Marvila e Matinha, criam fronteiras intra- e suburbanas. Desse processo de cisão, nascerão algumas das situações de abandono e de vacância que, segundo pautas diversas, se vão transformando ao longo do século XX e até aos nossos dias, de que são exemplo a Quinta do Marquês de 
Abrantes, seccionada pela linha de Circunvalação, partes significativas dos troços finais dos Vale de Chelas e de Alcântara e áreas localizadas na costeira norte de Lisboa, junto ao rio Trancão. Estruturas industriais e agrícolas em avançado estado de arruinamento coexistem num quadro topograficamente acidentado e, também por isso, resistente a uma reocupação mais recente. Pelo processo de segmentação e de cisão espacial que as produziu, estas áreas vacantes enquadram-se dominantemente no perfil de espaços fragmentados.

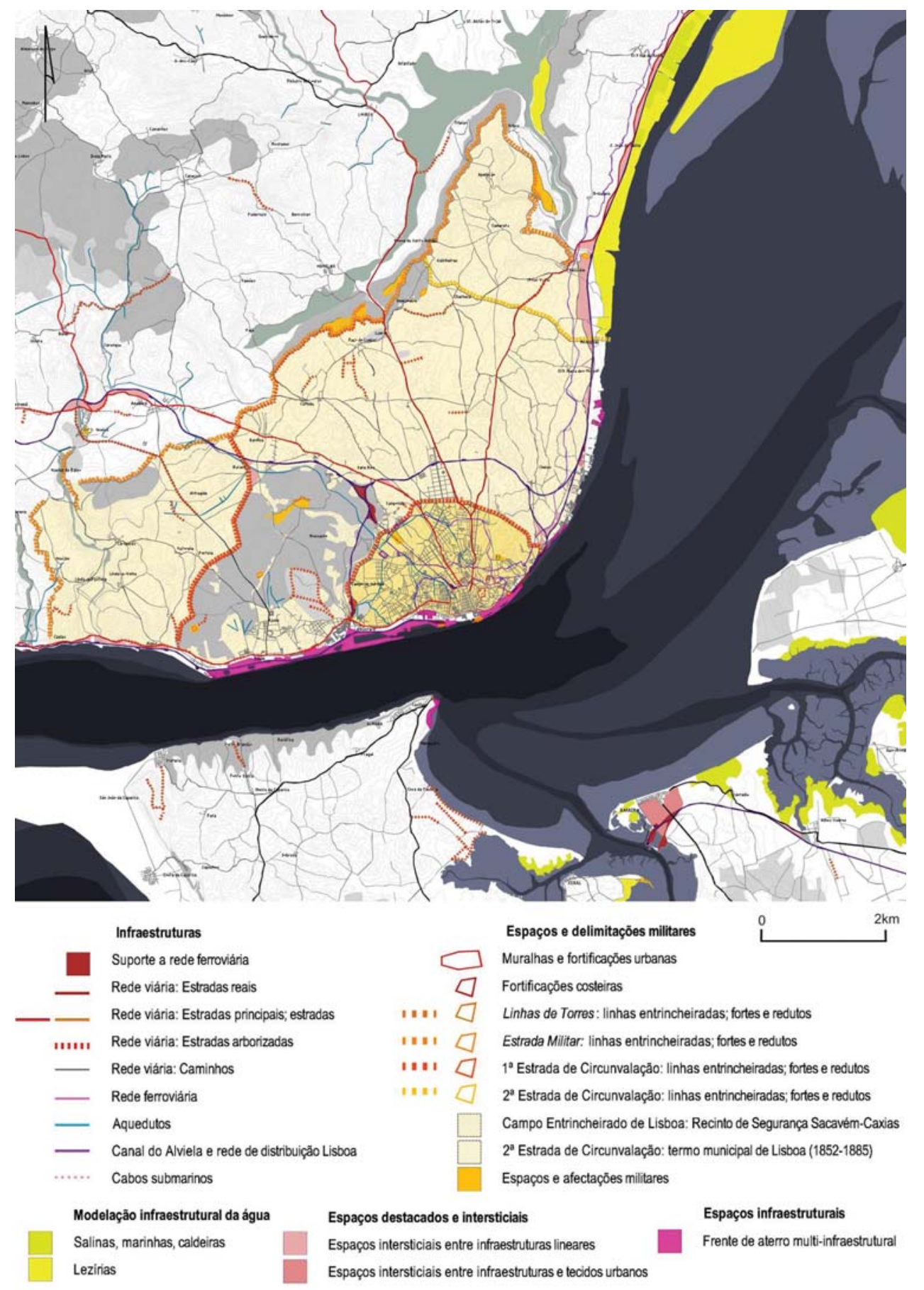

Fig. 1 - Interpretação cartográfica de redes infraestruturais em Lisboa - 1891 (com base em Santos, 2012). Figura a cores disponível online.

Fig. 1 - Cartographic interpretation of infrastructural networks in Lisbon - 1891 (based on Santos, 2012). Colour figure available online. 


\section{O ESPAÇO INFRAESTRUTURAL MODERNO: UMA COROA EQUIPADA E A MOBILIZAÇÃO DA MARGEM SUL}

O alargamento administrativo e infraestrutural da cidade de Lisboa é acompanhado pela programação e implementação de novos usos de apoio à cidade: um novo parque urbano de grandes dimensões, no que são hoje os terrenos da Cidade Universitária, apontado pelo Plano de Melhoramentos de 1903 de Frederico Ressano Garcia (Silva, 1989), o Mercado de Gados e a Praça de Touros, em Entrecampos/Campo Pequeno e o Hospital Curry Cabral. Já nas décadas de 1930/40, a florestação da Serra de Monsanto e o aeroporto da Portela definem sectores especializados de uma coroa equipada que se conjuga com as redes de abastecimento e de circulação anelar (fig. 2).

$\mathrm{Na}$ frente portuária, a organização do espaço de relação entre a cidade e o rio, profundamente artificializado ao longo do século XIX com a construção dos aterros do porto de Lisboa, resulta de uma combinação entre 1) a configuração da linha de costa (incluindo os sucessivos esteiros e reentrâncias associadas às ribeiras de Lisboa), 2) a profundidade e disposição dos fundos do estuário, 3) a resposta às lógicas, tecnologias e necessidades funcionais da navegação e estiva e 4) a organização de um espaço multi-infraestrutural, apto a responder às necessidades urbanas e industriais da capital. A configuração dos fundos e a hidrodinâmica do Tejo são fundamentais na modelação da frente portuária. A execução da $1^{\text {a }}$ secção do porto, entre Santa Apolónia e Alcântara, é adjudicada em 1887 a Pierre Hersent, seguida pela $2^{a}$ secção, entre Pedrouços e Alcântara. O novo terrapleno, conhecido como 'terrenos do Tejo', reconfigurou profundamente a relação da cidade com o rio, abrindo um espaço cuja vocação oscilou entre os usos industriais, portuários e infraestruturais e a expectativa - gorada - de ser uma nova área nobilitada de expansão da cidade.

Ainda sem a grande obra regularizadora, que só se desenvolve a partir dos anos 1950, a transformação da frente ribeirinha entre Santa Apolónia e o Beato modelou-se segundo lógicas mais parcelares, mas também determinadas por uma logística industrial e de movimentação de mercadorias pelo rio e estuário do Tejo. De facto, as relações com a margem esquerda são fundamentais na consolidação e crescimento industrial da Lisboa ribeirinha. Na margem sul, onde a aglomeração urbana é substancialmente mais rarefeita, só a partir de meados do século XIX se assiste ao desenvolvimento embrionário da atividade industrial. As primeiras formações estão associadas a quintas ribeirinhas, nas orlas das povoações (Cruz, 1973; Rodrigues, 1999). É o caso do Barreiro, onde quintas como a de São Francisco, Braamcamp ou Palhais, recebem unidades de transformação de cortiça, de cordoaria e de seca de bacalhau. Mas é com a construção, a partir de 1907, das primeiras unidades fabris da CUF - Companhia União Fabril, que se desenvolve o que viria a constituir o maior conglomerado industrial do país, verticalmente integrado, com atividades diversificadas, mas interdependentes (Silva, Gomes, \& Cruz, 2004). As áreas ribeirinhas situadas a norte da antiga estrada Barreiro-Lavradio são aterradas, regularizando uma vasta área; é sobre ela que se organiza uma malha interna de ramais ferroviários e uma métrica regular de implantação fabril. A geometria da nova frente de cais e a dragagem do canal da CUF, permitem a navegação e a acostagem nos terminais especializados do complexo. 
A transformação de espaços ribeirinhos sob efeito de novas infraestruturas e de ocupações industriais reforça o sentido infraestrutural dos elementos hidro-fisiográficos, agora potenciados pela artificialização das suas margens e dos seus fundos. A relação umbilical entre a margem e o tecido urbano é, a partir de agora, mediada por um espaço mais regular, planificado, aberto a múltiplas formas de ocupação e uso, mas que é também um elemento de descontinuidade e rotura.

Atualmente, identificam-se, nestes territórios de aterro portuário e industrial, áreas significativas sem utilização e já objeto de demolição de estruturas fabris. Os casos da antiga CUF, no Barreiro, e da Lisnave, em Almada, são os mais expressivos, não só pela dimensão e impacte na organização do espaço urbano, mas também pela condição infraestrutural que lhes permite continuarem a ser o suporte para projetos de reconversão, como o Plano de Urbanização da Quimiparque e o Plano de Urbanização de Almada Nascente. Quando observados de forma comparativa com outras frentes de aterro onde se perdeu a função portuária e/ou industrial - como o caso da secção Pedrouços-Alcântara-Cais do Sodré, em Lisboa - compreende-se que a vacância corresponde a um estado potencialmente transitório, sujeito a oportunidades e dinâmicas que a cada momento se colocam - no caso de Lisboa, como suporte para usos recreativos e culturais. Nesse sentido, enquadram-se dominantemente no perfil de plataformas infraestruturais, em transição funcional.

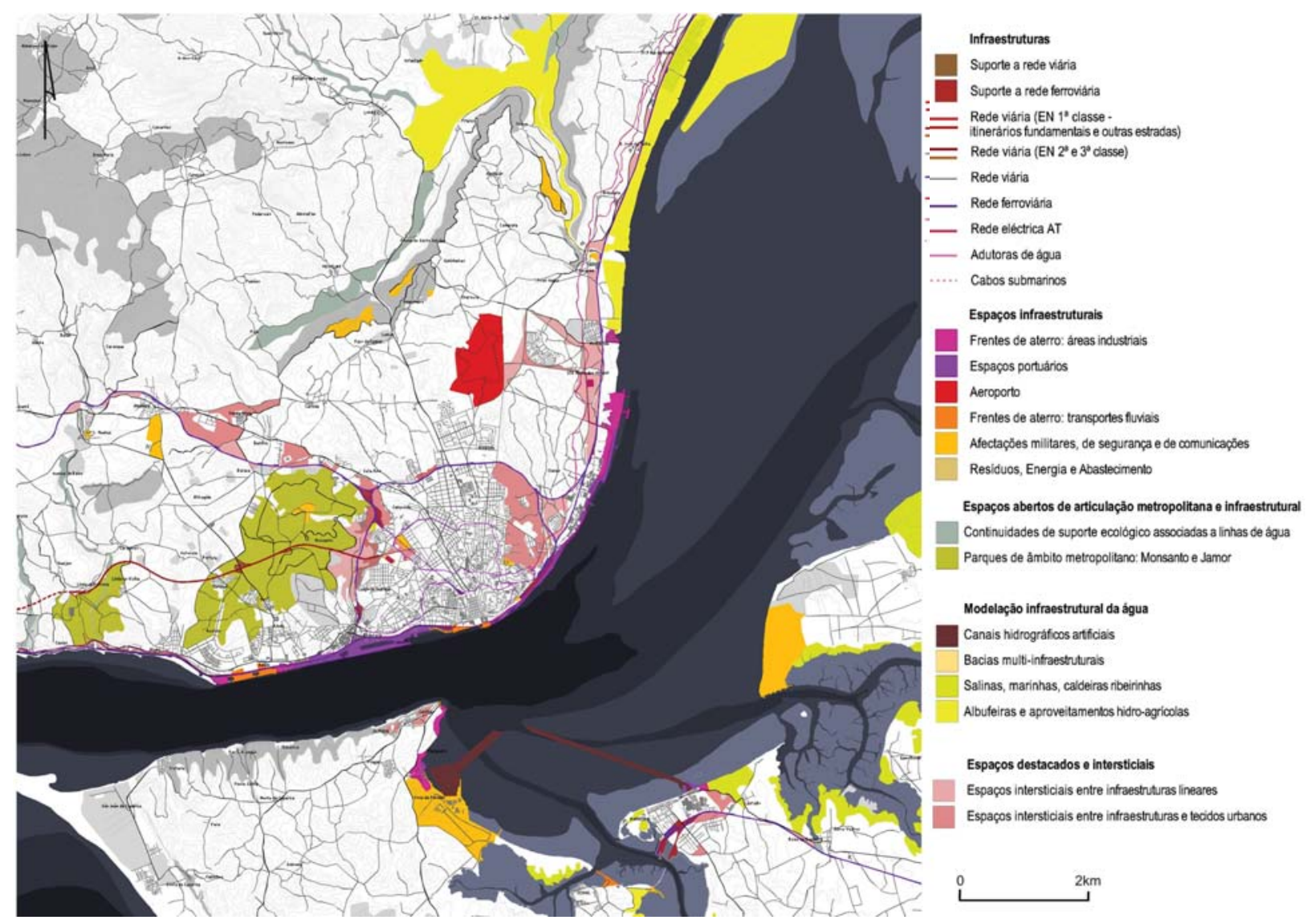

Fig. 2 - Interpretação cartográfica de redes infraestruturais em Lisboa - 1944 (com base em Santos, 2012). Figura a cores disponível online.

Fig. 2 - Cartographic interpretation of infrastructural networks in Lisbon - 1944 (based on Santos, 2012). Colour figure available online. 


\section{ENTRE A OBRA PÚBLICA E O FOMENTO INDUSTRIAL: A FORMAÇÃO DE SOLO PORTUÁRIO E INDUSTRIAL}

Com a Lei de Reconstituição Económica de 1935, o investimento público é dirigido para obras de estradas, portos, edifícios públicos, barragens e aproveitamentos hidroagrícolas e instalações de defesa. Mas a este protagonismo da obra pública (Santos, 2013), protagonizado por Duarte Pacheco, segue-se um realinhamento económico e produtivo do país no pós-guerra, agora decididamente orientado pela visão industrialista (Brito \& Rollo, 1996; Caetano, 2008).

Uma das obras mais importantes é o reforço do abastecimento de água à capital com a construção do Canal Tejo (1935-1940) (Veiga da Cunha, 1948), duplicando o canal infraestrutural do Alviela. A zona dos Olivais é reforçada como nó infraestrutural com a implantação do reservatório principal do sistema, a partir do qual se potencia o abastecimento à coroa urbana da capital. No que diz respeito ao gás, a nova fábrica da Matinha (1944) substitui a de Belém e impulsiona a construção de uma rede de distribuição apoiada nas novas vias dos sectores norte e este da cidade (2a Circular, Av. Marechal Gomes da Costa, Av. do Brasil, Av. Infante D. Henrique) (Matos, 2009). Inverte-se, assim, o sentido radial do abastecimento de gás, numa lógica semelhante à que já se referenciou para a água.

Numa escala bem mais alargada do que a do gás, é no domínio da eletricidade que se estabelecem as bases da rede elétrica nacional, instrumento fundamental de suporte aos novos sectores industriais (Rollo \& Brito, 1996; Custódio, 2005). A barragem de Castelo de Bode, concluída em 1951, representa um passo decisivo 1) pela definição de um corredor primário de transmissão elétrica desde o Zêzere até Lisboa, ao longo do Tejo, 2) pela progressiva desativação das antigas centrais que operavam de forma dispersa nos diversos municípios, de que se destaca a Central Tejo, e 3) pelo fomento da indústria pesada alimentada pela eletricidade (eletroquímica, eletrossiderurgia e eletrificação da ferrovia).

A 'exteriorização' do abastecimento e da circulação de âmbito nacional e metropolitano (água, eletricidade, gás, vias arteriais) face aos antigos tecidos compactos e ribeirinhos da cidade, conforma uma coroa infraestrutural que, mais do que um limite, absorve a espessura entre as circunvalações e disponibiliza espaço para os equipamentos nodais de cada rede (subestações, reservatórios, depósitos). Para além da ordem estritamente infraestrutural, é nessa coroa que se circunscrevem áreas industriais e residenciais especializadas, suportadas por uma armadura viária de características modernas, dissociada e hierarquizada face à rede axial e local existente (Olivais, Cabo Ruivo) (fig. 3).

À exteriorização do abastecimento e da circulação da cidade de Lisboa, corresponde também a relocalização de boa parte do seu aparato industrial na margem sul do Tejo, apoiada num programa de reforço infraestrutural da península de Setúbal. Prevê-se a construção de uma robusta rede ferroviária a sul do Tejo, associada à travessia entre Alcântara e Almada e a vastas áreas industriais e portuárias a conquistar nas margens do rio (Gomes, 2005). É nessa linha que se formatam os projetos do canal Tejo-Sado e da deslocação do aeroporto internacional de Lisboa para Rio Frio (Gabinete do Plano Director da Região de Lisboa (GPDRL), 1964). 
A abertura do primeiro troço da autoestrada do Norte (A1) entre Sacavém e Vila Franca de Xira, em 1961, dez anos depois da abertura da ponte Marechal Carmona, potencia uma combinação paralelística com a linha do Norte, com a frente de aterros portuários em Cabo Ruivo, com um canal de águas profundas dragado do rio Tejo, e com os vários canais de abastecimento de água e eletricidade. Estabelece-se assim um potente efeito de axialidade de escala nacional que se projeta sobre a área central do rio Tejo, associando infraestruturas e tecidos de âmbito urbano com espaços e infraestruturas de âmbito metropolitano. $\mathrm{O}$ rio e os seus fundos navegáveis passam a estar integrados nesse estrato invisível de reticulação infraestrutural, deslocando o centro topológico da paisagem industrial da região para o plano central do estuário do Tejo. O porto de Lisboa desdobra-se, então, num complexo urbano-portuário de maior interdependência funcional e espacial entre as duas margens, complementado por novos complexos na margem sul: Alfeite, Margueira, Lavradio, Paio Pires e, mais a jusante, na Trafaria, Porto Brandão e Banática.

No que respeita à frente oriental de Lisboa e ao corredor de Vila Franca de Xira, a Administração Geral do Porto de Lisboa, no seu Plano de Melhoramentos aprovado em 1946, orienta-se para a afirmação como porto terminal de linhas internacionais e grande entreposto de produtos das colónias e do Brasil. No sector entre Cabo Ruivo e Beirolas estabelece-se a implantação da "nova zona industrial da cidade" (Administração Geral do Porto de Lisboa (AGPL), 1948), antecipando-se uma futura intervenção na foz do Trancão para apoio à crescente atividade industrial de Sacavém. É também para este sector que se programam grandes equipamentos de suporte da própria cidade (Câmara Municipal de Lisboa (CML), 1967), como o Matadouro, o Aeroporto Marítimo, a Fábrica Nacional de Munições do Exército em Moscavide, o Parque de Material de Guerra e o aterro sanitário em Beirolas e a estação de autocarros de Cabo Ruivo.

$\mathrm{Na}$ confrontação com a atualidade, os espaços infraestruturais produzidos neste período têm vindo a inscrever-se progressivamente no tecido urbano da cidade: por um lado, através do preenchimento e da colmatação edificada das linhas axiais e da coroa equipada, por outro, pela reconversão do final do século XX de parte significativa da zona industrial oriental da cidade. Mais do que espaços de dimensão significativa, identificam-se estruturas edificadas abandonadas e respetivos recintos, decorrentes da nova geografia das redes de produção e abastecimento, com a desativação de centrais elétricas (Central Tejo), de centrais e depósitos de gás (Pedrouços, Infante Santo, Matinha) ou de abastecimento de água (Barbadinhos), para além de múltiplas unidades industriais (Cabo Ruivo, Sacavém, Sorefame-Reboleira). Algumas foram objeto de reconversão (Central Tejo, Barbadinhos), muitas outras de demolição e reocupação (nova sede da EDP, várias unidades fabris em Cabo Ruivo). Os espaços vacantes que persistem deste processo, enquadram-se dominantemente, no perfil de estruturas arruinadas e recintos abandonados. 


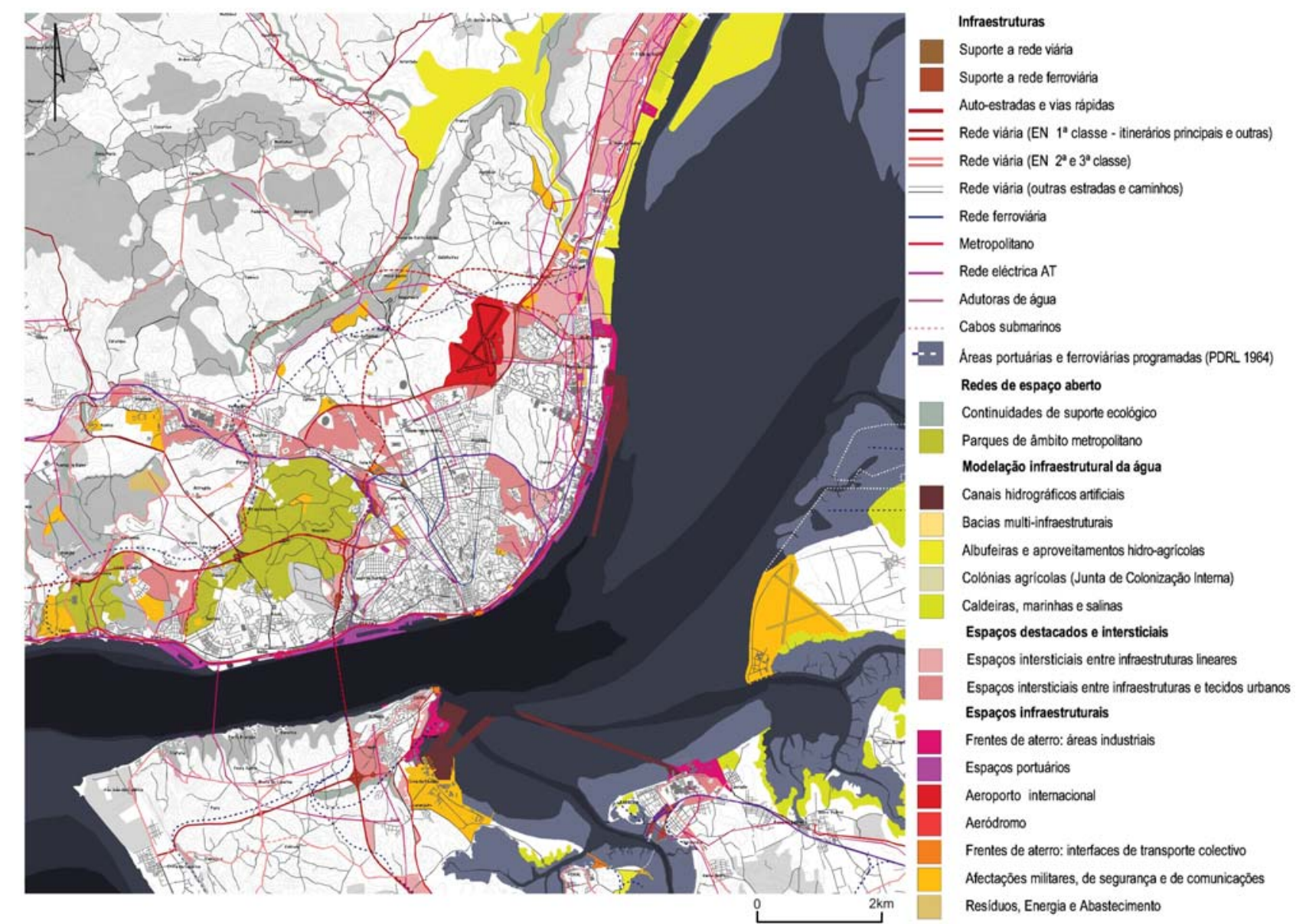

Fig. 3 - Interpretação cartográfica de redes infraestruturais em Lisboa - 1966 (com base em Santos, 2012). Figura a cores disponível online.

Fig. 3 - Cartographic interpretation of infrastructural networks in Lisbon - 1966 (based on Santos, 2012). Colour figure available online.

\section{ROTURA INFRAESTRUTURAL: A DESAGREGAÇÃO DAS MARGENS E A MULTIPLICAÇÃO DE INTERSTÍCIOS}

Após um período de grande dinamismo no sector das obras públicas, a degradação das condições económicas no final da década de 1960, resultantes do esgotamento do modelo produtivo e da guerra colonial, traduzem-se numa forte desaceleração do ritmo de investimentos em infraestruturas. Com o protelar da execução de diversas obras previstas, como a rede de vias rápidas regionais, acentuam-se desequilíbrios, cada vez mais sensíveis, entre o crescimento urbano e demográfico e a necessária cobertura de infraestruturas gerais e locais.

É neste contexto que emergem novos processos de formação urbana sobre um mosaico que, continuando referenciado à matriz rústica, passa a operar como suporte direto de urbanização. Ou seja, a desagregação da exploração agrícola e florestal que ainda persiste em parte significativa da metrópole, alarga de forma extensiva as oportunidades de fracionamento e loteamento urbanos (Cavaco, 2009; Santos, 2012). Nesse processo, verifica-se 
uma desvinculação entre o suporte infraestrutural e o espaçamento do edificado e a produção de um mosaico paratático, onde se confrontam tecidos de baixa densidade com loteamentos baseados na edificação em altura (Nunes, 2011; Santos, 2012). Os espaços de transição e de limite são, precisamente, os que de forma mais evidente refletem as tensões e contradições de um território sub-infraestruturado e precariamente articulado: entre tecidos de génese diferenciada e em acelerada mutação, nos conflitos entre a estrutura ecológica e a ocupação edificada, na tensão entre a potente indução conectiva de novas vias rápidas e a frágil capilaridade de estradas e caminhos locais.

A coroa infraestrutural equipada da cidade de Lisboa, destacada no período anterior, é agora, e paradoxalmente, a base sobre a qual se desenvolve parte significativa desta ocupação precária sem qualquer tipo de infraestruturação. As áreas expropriadas em períodos anteriores no âmbito da programação urbanística (vale de Chelas, Musgueira, Alto dos Moinhos, Quinta dos Barros), ou afetadas pela contiguidade a grandes infraestruturas como o aeroporto, a $2^{\text {a }}$ Circular, a autoestrada do Norte (Prior Velho, Portela, Quinta do Mocho), ou os acessos à ponte 25 de Abril (Casal Ventoso, Furnas, Liberdade) são ocupadas de forma expedita e segundo padrões de grande informalidade e organicidade. Nestes casos, a descontinuidade transversal provocada pelas infraestruturas pesadas cria as condições para o aproveitamento de áreas que ficaram funcionalmente e espacialmente destacadas das unidades em que se inscreviam anteriormente, e que se encontram num estado de latência e expectativa ante futuras transformações. Nos limites do município de Lisboa com Oeiras, Amadora e Loures e na Estrada Militar Sacavém-Caxias, encontram-se formações precárias associadas a delimitações administrativas, a servidões militares descontinuadas e a terrenos de forte declive.

Durante os primeiros anos deste período, a transformação do território metropolitano continua a apoiar-se fundamentalmente na rede ferroviária e numa rede viária arterial insípida, rebatida sobre antigas estradas nacionais e municipais de capacidade limitada, com exceção da construção da ponte sobre o Tejo, em Almada, em 1966, e do primeiro lanço da autoestrada do Sul (A2). Na península de Lisboa, é lançado um novo eixo radial arterial, com a construção da avenida Padre Cruz e continuação a Loures e Malveira pela A8 e, já na década de 1990, dá-se a conclusão da A5 entre o Estádio Nacional e Cascais, do IC 19, de troços da CRIL (Alto do Duque-Buraca em 1993), da CREL e da radial de Odivelas (ambas em 1995; fig. 4).

Fica patente uma organização que se diferencia das primeiras etapas de reticulação metropolitana assente nas autoestradas das décadas de 1940 a 1960. Agora, mais do que indutoras e estruturadoras de profundas transformações em espaços de baixa ocupação urbana ou combinadas com o fomento de polos industriais, as novas vias rápidas são entendidas como elementos 'complementares' de uma rede radio-concêntrica e como suporte de uma urbanização precariamente articulada, equipada e infraestruturada (Barreiros, 1988). Inverte-se o papel convencionalmente imaginado da infraestrutura, como diretriz de desenvolvimento, passando a ocupar precisamente os intervalos que medeiam entre uma rede saturada de uma metrópole monocêntrica e as respostas possíveis de uma urbanização frágil. 
É também nesse contexto que se vão estabelecendo soluções diversificadas de aproveitamento dos espaços de contacto e adjacência às novas infraestruturas. Hortas e mosaicos improvisados de agricultura de subsistência, recintos desportivos de pequena dimensão e utilização informal, espaços verdes de utilização coletiva ou bases para implantação de elementos publicitários, antenas de telecomunicações ou linhas elétricas, são alguns dos programas que passam a constituir um léxico da paisagem infraestrutural metropolitana.

É ainda neste período que se fazem sentir os efeitos da transição macroeconómica para um paradigma pós-industrial. Se até aos anos 1960 o Tejo continua a ser o ponto focal de todas as linhas infraestruturais (ferroviárias, rodoviárias, energéticas, marítimas), após a desagregação do mercado colonial e com a introdução das ligações continentais à Europa, parte significativa do seu protagonismo funcional é atingida. É um processo que afeta, em simultâneo, $\mathrm{o}$ arco industrial da margem sul, Alcântara e a frente industrial de Xabregas a Cabo Ruivo e Sacavém, confirmando o carácter transversal da mutação em curso. A desconcentração territorial de uma nodalidade energética e portuária, deslocada em direção a Setúbal, Marateca e Sines, evidencia não só a alteração de uma lógica produtiva e infraestrutural, mas é também fator fundamental para uma conceção renovada do Tejo enquanto centro simbólico e paisagístico da metrópole (Matias Ferreira \& Indovina, 1999).
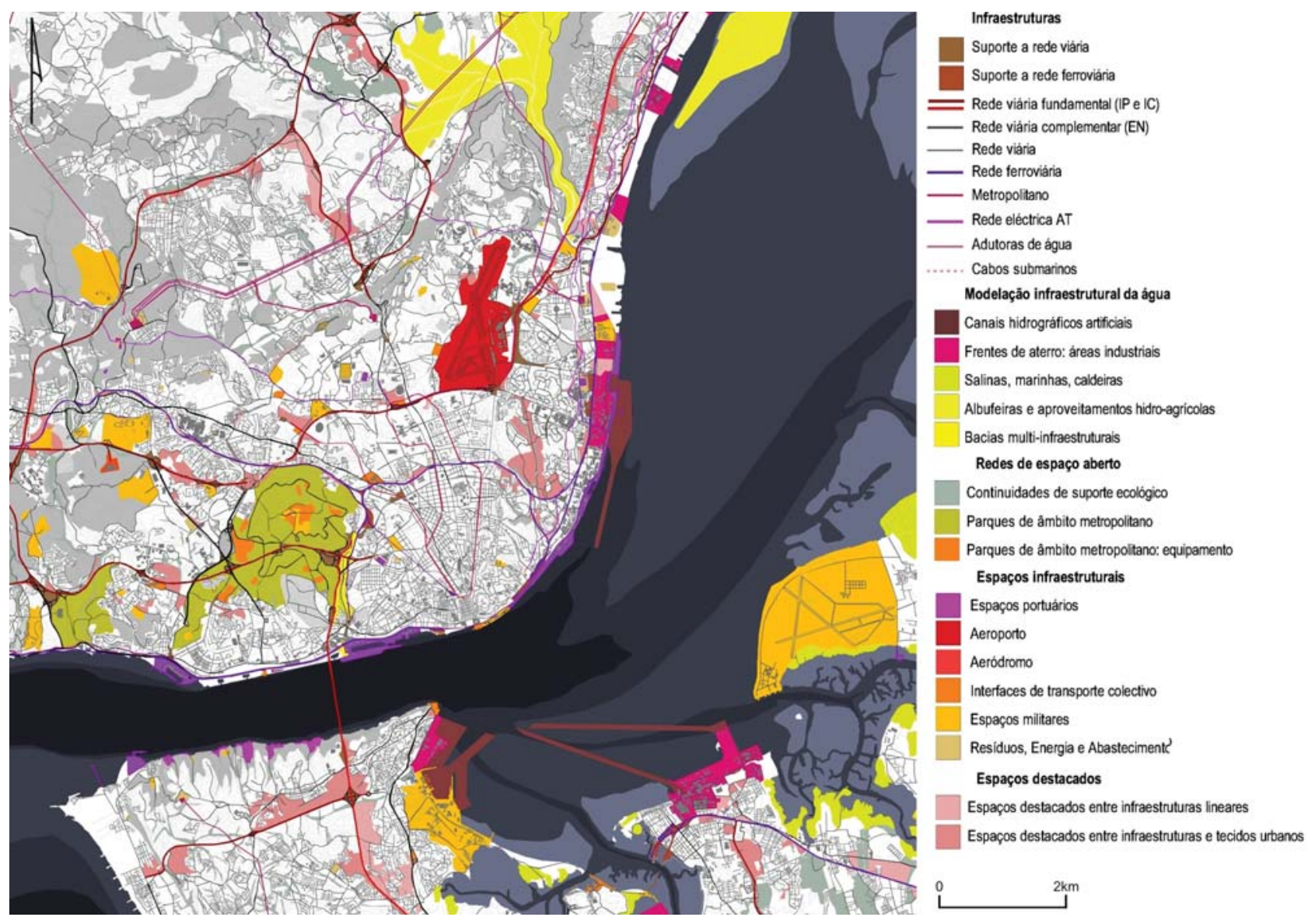

Fig. 4 - Interpretação cartográfica de redes infraestruturais em Lisboa - 1995 (com base em Santos, 2012). Figura a cores disponível online.

Fig. 4 - Cartographic interpretation of infrastructural networks in Lisbon - 1995 (based on Santos, 2012). Colour figure available online. 
Mais próximos da atualidade, os espaços vacantes produzidos neste período resultam, por um lado, da continuidade do processo de reconfiguração dos sistemas infraestruturais e do tecido produtivo observado no ponto anterior, e, por outro, da multiplicação de áreas adjacentes a vias rodoviárias, a linhas elétricas de alta-tensão a grandes equipamentos e zonas logísticas, nomeadamente na envolvente ao aeroporto de Lisboa ou no eixo Moscavide-Sacavém-Bobadela. Estas áreas vacantes constituem resíduos da sobreposição de múltiplas servidões, espaços-canais e áreas non-aedficandi, mantendo, por vezes, usos e apropriações de alguma informalidade e marginalidade, podendo ser enquadrados no perfil de espaços intersticiais.

\section{UM TECIDO CONECTIVO: UMA PAISAGEM COMPÓSITA}

É durante o período de 1995-2007 que se torna mais clara - quer para o grande público, mas sobretudo para a administração - que a natureza metropolitana deste território exige respostas diversificadas face a tensões e assimetrias internas (Barata Salgueiro, 2001; Pinheiro, Baptista, \& Vaz, 2001), mas também cada vez mais referenciadas a uma inserção num contexto globalizado. A conceção do território como valia internacional, plasmado em instrumentos de natureza estratégica nacional, de políticas de cidade (Portas et al., 2003) e de mecanismos operativos de intervenção urbana, permite delinear como prioridades de intervenção a melhoria das condições de conectividade funcional (mobilidade e comunicação), a dinamização das economias urbanas baseadas em clusters de terciário especializado (TIC, I\&D, logística, saúde, turismo) (Escária \& Ribeiro, 2010) e o cruzamento da dimensão ambiental e da qualidade espacial como componentes centrais na lógica da sustentabilidade territorial.

No domínio da dotação de novas redes infraestruturais (fig. 5), salienta-se o reforço da acessibilidade interna, entre as duas margens do Tejo, pela construção da ponte Vasco da Gama e pela introdução de uma linha ferroviária na ponte 25 de Abril que, servindo o eixo Almada-Coina-Setúbal, encerra o anel viário em torno do estuário do Tejo e permite ligações ferroviárias diretas entre Lisboa e o sul do país. Com a abertura da CREL em 1995 e da CRIL, com aberturas faseadas entre 1995 e 2011, constitui-se o suporte do sistema viário alternativo às linhas radiais que dominavam a organização do território. A CRIL e a CRIPS permitem o atravessamento anelar das penínsulas de Lisboa e Setúbal. Em Lisboa, reforçam-se as acessibilidades do sector nordeste da cidade e de Sacavém e Moscavide, em grande parte impulsionado pelos acessos à Expo 98 / Parque das Nações (IC 2 e reperfilamento, desnivelamentos e conclusão da Av. Infante D. Henrique, conclusão do Eixo Norte-Sul, extensão do metropolitano, construção da Gare do Oriente).

Mas é sobretudo no domínio da articulação externa, nos suportes logísticos e na recomposição das infraestruturas de abastecimento que se operam maiores transformações, colocando em evidência coroas exteriores do território metropolitano e espoletando a programação de novas formas de ligação da metrópole às redes globais. É este suporte mais reticulado (novas redes, e com efeito de rede), multi-infraestrutural e intermediário (entre escalas) que sustem uma matriz metropolitana mais coesiva, de contornos 
hierárquicos mais diluídos e de maior resiliência face às fragilidades, roturas e insuficiências que, após décadas de pressão demográfica e crescimento urbano intensos, se faziam sentir no dia-a-dia da área metropolitana.

Uma das principais inovações na organização infraestrutural é do reforço das lógicas de interfacialidade (Santos, 2012), não só com a conclusão de várias ligações intermodais, mas também pelas oportunidades de articulação urbanística que se constroem na sua envolvência. É sobre estes espaços de interfacialidade que se produzem novas articulações com a estrutura ecológica e com novos espaços públicos, novas práticas de consumo e racionalidades locativas e funcionais do tecido económico. É neste contexto que se ensaiam formas de intervenção mais excecionais para áreas marcadas pela obsolescência funcional e desqualificação espacial e ambiental. Identificam-se dois princípios dominantes de intervenção: 1) a formatação de operações de regeneração urbana e ambiental de grande escala, associadas a antigas áreas industriais e dependentes de um relacionamento intenso com infraestruturas de âmbito metropolitano e 2) a estruturação de espaços associados a frentes ribeirinhas contínuas, com recurso a projetos combinando elementos urbanos, agrícolas e naturais, e tendo a água como denominador comum.

As primeiras procuram responder ao fenómeno da desindustrialização (André \& Vale, 2012), que se faz sentir em espaços bem infraestruturados e próximos de rios. Apesar das excelentes condições infraestruturais e protagonismo ambiental, cénico e simbólico, enfrentam uma herança pesada de múltiplos passivos ambientais. As circunstâncias excecionais de investimento e de dinâmica imobiliária que se verificaram aquando da construção da Expo 98 / Parque das Nações (Cabral \& Rato, 2003) não parecem vir a repetir-se, como atesta a latência que se identifica em outras áreas próximas. A reorganização, compactação e modernização do sistema portuário e logístico da faixa entre Santa Apolónia e a Matinha ainda não foi acompanhada pela implementação de projetos urbanos previstos para a área de Marvila, Braço de Prata e Matinha. Na margem sul, as áreas da Lisnave, Siderurgia Nacional e Quimiparque enfrentam grandes incertezas e um estado de latência prolongado. No caso do Barreiro, foi elaborado um plano de urbanização para a reestruturação da Quimiparque, que passa precisamente pelo aproveitamento do potencial infraestrutural dos aterros conquistados ao rio e às salinas do Lavradio para receber a programada Terceira Travessia do Tejo (Chelas-Barreiro) e um novo espaço logístico e portuário complementar aos terminais principais do porto de Lisboa.

Se a estrutura de mobilidade é uma das alavancas de processos de requalificação e regeneração urbana, também se recorre a outros elementos infraestruturais na sutura de diversas roturas morfológicas e ambientais. Reconhecem-se como suportes potenciais de um tecido conectivo (Santos, 2012), as linhas fisiográficas e hidrográficas estruturantes da metrópole e os intervalos residuais e desagregados. Estes elementos constituem-se como material constituinte de projetos urbanos de envergadura variável, multidimensionais ou com recurso a estratégias mais leves e discretas (Santos, 2017). Destacam-se os que exploram sinergias multi-infraestruturais ao longo de bacias de drenagem hidrográfica (ribeiras de Algés, de Alcântara, do Prior Velho, rio da Costa), reinterpretando uma combinação olmsteadiana entre espaços coletivos e o suporte ecossistémico da cidade (Farhat, 2011). 
As transformações ocorridas entre 1995 e 2007 produzem um estado particularmente revelador do que há de metropolitano no território metropolitano de Lisboa. A reticulação dos múltiplos sistemas infraestruturais ganha uma densidade e robustez multi-escalar; as formas de produção de tecido metropolitano passam a acomodar as capilaridades e singularidades de espaço aberto e da rede ecológica. Colmatadas as principais fragilidades infraestruturais à escala metropolitana, as estratégias delineadas com a aprovação do Programa Nacional da Politica de Ordenamento do Território (PNOPT) e no processo de revisão do Plano Regional de Ordenamento do Território da Área Metropolitana de Lisboa (PROTAML), orientam-se agora para questões de coesão, qualificação e eficiência na utilização dos recursos territoriais e para a integração em redes globais de acessibilidade e conectividade. No entanto, após a crise financeira global de 2008, esta dinâmica fica em suspenso, num cenário de re-aferição, adiamento ou cancelamento de investimentos infraestruturais, a par de uma retração de investimento e de consumo privado. A última década oscila, assim, entre a redefinição de um projeto metropolitano, a interrupção, mais ou menos prolongada, de um ciclo de crescimento residencial suburbano expressivo, e a recomposição de microdinâmicas associadas a nichos do mercado imobiliário.
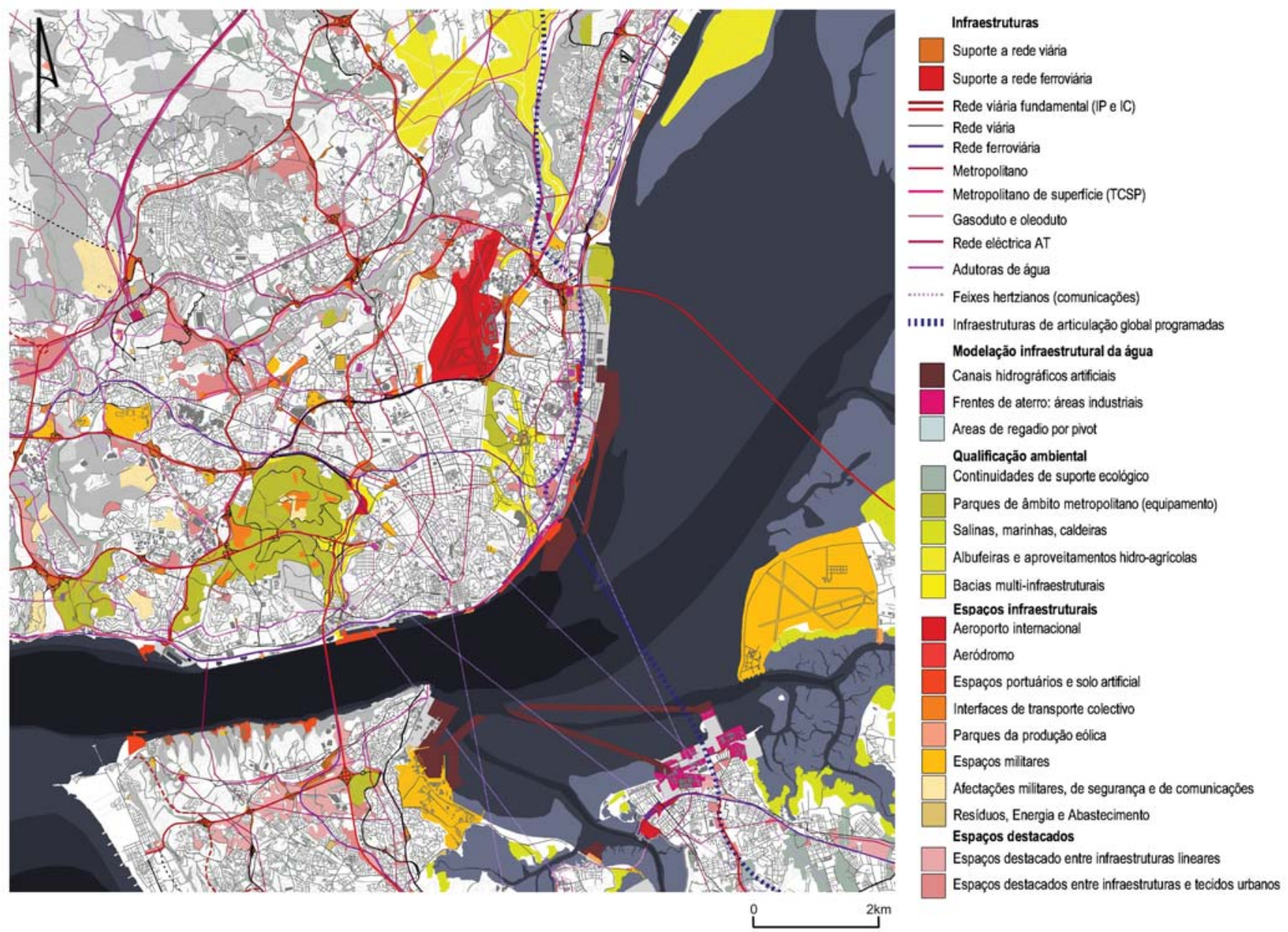

Fig. 5 - Interpretação cartográfica de redes infraestruturais em Lisboa - 2007 (com base em Santos, 2012). Figura a cores disponível online.

Fig. 5 - Cartographic interpretation of infrastructural networks in Lisbon - 2007 (based on Santos, 2012). Colour figure available online. 
É neste quadro que emergem novas situações de vacância associadas a áreas recentemente urbanizadas que veem o processo de edificação, respetiva comercialização e ocupação interrompido face à crise económica e financeira de 2008 (Brito-Henriques, 2017), mas também as que se associam a projetos infraestruturais suspensos. É o caso das áreas de amarração da Terceira Travessia do Tejo em Lisboa (Beato/Marvila) e no Barreiro (Quimiparque/IC20). Um e outro caso poderão enquadrar-se no perfil dos espaços suspensos.

\section{CONCLUSÃO}

Para cada etapa de produção do território metropolitano destacaram-se os carateres que mais diretamente se relacionam com o suporte infraestrutural. Dessa identificação, baseada fundamentalmente na introdução, adição e sobreposição progressiva de novas redes, poder-se-á também deduzir, de forma sintética, alguns dos carateres associados aos espaços marcados pela vacância na atualidade (fig. 6).

Neste caso, já não é através de processos aditivos que se pode fazer esse reconhecimento, mas, inversamente, através de operações de remoção, interrupção, cisão e desagregação espacial e funcional. A estas operações associam-se dinâmicas económico-sociais tendencialmente regressivas e de declínio que, de forma estrutural ou circunstancial, infletem processos de reprodução urbana e territorial. No entanto, mesmo uma dinâmica regressiva é modelada pela indelével presença de suportes e de redes. Também no declínio, abandono e arruinamento, o território e a cidade não são isotrópicos. As condições infraestruturais que presidem à sua formação, crescimento e expansão, são também determinantes nos processos inversos.

Na segunda metade do século XIX, em plena Regeneração e respondendo à introdução de transportes mecanizados, são os espaços cindidos pela sobreposição de linhas infraestruturais (como a linha do Norte e o Campo Entrincheirado) que se reconhecem como resíduos, descontínuos e esvaziados de uma racionalidade de uso; com os aterros do Tejo e a cintura ferroviária, é na paisagem dos vales e dos limites fisiográficos da cidade que se operam maiores roturas; com a industrialização e aposta num suporte mais robusto de obras públicas nas duas décadas após a $2^{\text {a }}$ Guerra Mundial, desmobiliza-se da exploração agrícola a coroa rústica que envolvia a cidade oitocentista; com a intensificação e extensão do crescimento suburbano e a construção de vias rápidas, é nos interstícios, nos espaçamentos anódinos e nas primeiras expressões de desindustrialização que se encontram traços de vacância e indeterminação; na transição para o século XXI, são os grandes complexos industriais, os cascos urbanos mais antigos e os fragmentos de espaço aberto circunscritos por frentes urbanas dispersivas que constituem o estrato mais expressivo da vacância. Finalmente, reconhecem-se nos tempos mais recentes as situações de urbanização interrompida e de vacância na ocupação de novos edifícios, pressionando a sustentação económica e fiscal das redes urbanas existentes. 
Independentemente do programa para uma sua valorização, os espaços de vacância associados a suportes infraestruturais constituem uma matriz genética do território metropolitano. São memórias inscritas no seu palimpsesto urbano e traços construídos de um património cujo registo, mapeamento e caracterização constitui um instrumento com potencial operativo na orientação de políticas e de iniciativas mais ou menos formalizadas, perenes ou efémeras de projeto urbano e territorial.

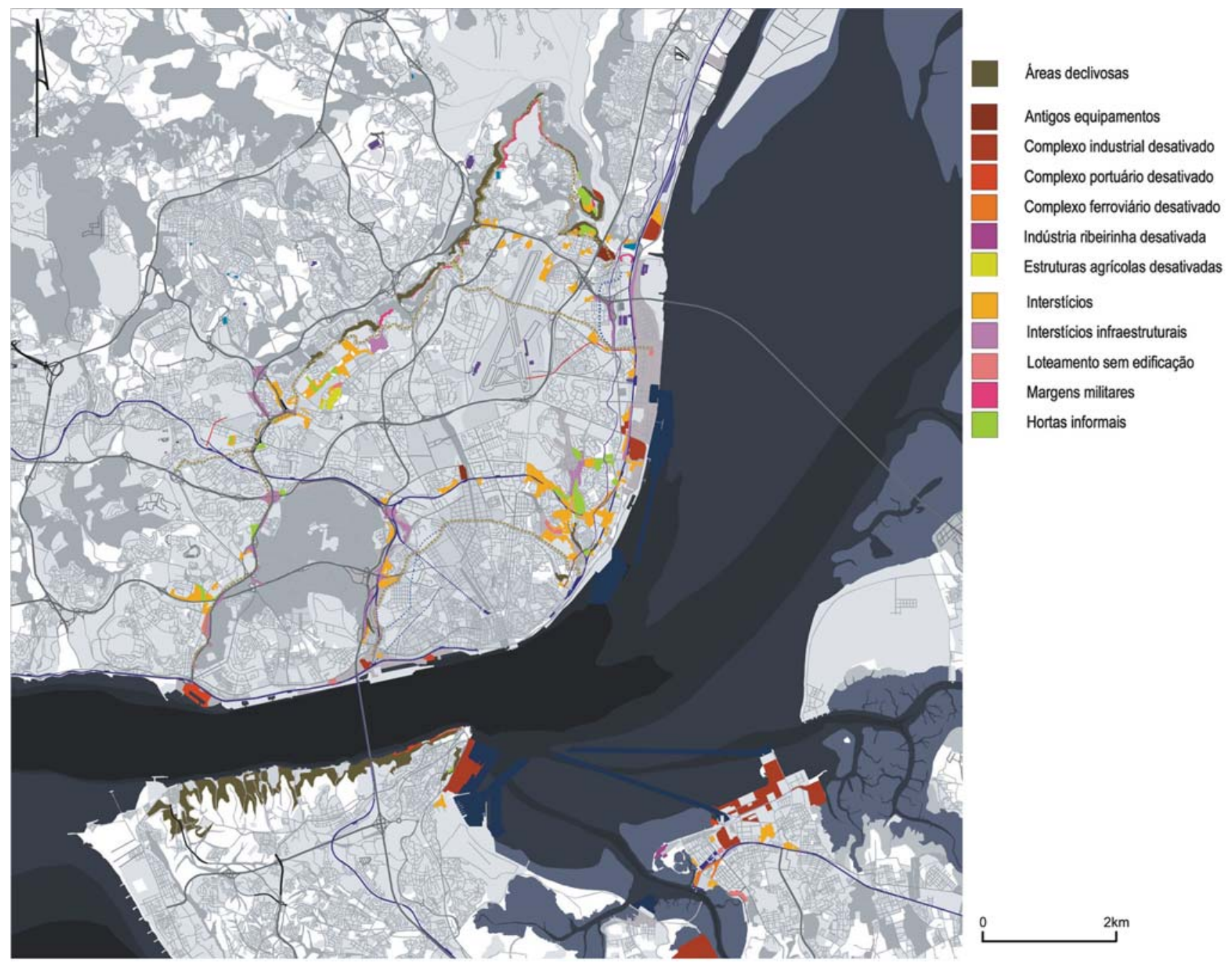

Fig. 6 - Interpretação cartográfica de espaços vacantes associados a infraestruturas na área central do território metropolitano de Lisboa - 2017. Figura a cores disponível online.

Fig. 6 - Cartographic interpretation of vacant spaces associated with infrastructures in the central area of Lisbon's metropolitan territory - 2017. Colour figure available online.

\section{AGRADECIMENTOS}

Este trabalho é financiado por fundos nacionais através da FCT - Fundação para a Ciência e a Tecnologia, I.P., no âmbito do Projeto PTDC/ATP-EUR/1180/2014 NoVOID- Ruínas e Terrenos Vagos nas Cidades Portuguesas: Explorando a Vida Obscura dos Espaços Urbanos Abandonados e Propostas de Planeamento Alternativo para a Cidade Perfurada, recorrendo parcialmente a dados resultantes da investigação financiada pela Bolsa de Doutoramento SFRH/BD/38002/2007. 


\section{REFERÊNCIAS BIBLIOGRÁFICAS}

Administração Geral do Porto de Lisboa. (AGPL). (1948). Plano de Melhoramentos do Porto de Lisboa [Improvements Plan for the Port of Lisbon]. Lisboa: Ministério das Comunicações/AGPL.

Alegria, M. F. (1990). A organização dos transportes em Portugal (1850-1910). As vias e o tráfego [The organization of transports in Portugal (1850-1910). Roads and traffic]. Lisboa: Faculdade de Letras, Universidade de Lisboa.

Alonzo, É. (2007). La voie en ruine [The road in ruins]. In C. Prelorenzo \& D. Rouillard (Dirs.), Le temps des infrastructures [The time of infrastructures] (pp. 71-81). Paris: L'Harmattan.

André, I., \& Vale, M. (2012). Lisboa: tensiones entre ciudad y la metrópoli [Lisbon: tensions between the city and the metrópolis]. In M. Balbo (Ed.), Europa: la ciudad central en el sistema urbano [Europe: the central city in the urban system] (pp. 209-239). Quito: Organización Latinoamericana y del Caribe de Centros Históricos.

Appleyard, D., Lynch, K., \& Myer, J. R. (1964). The View from the Road. Cambridge, MA: MIT Press.

Banham, R. (1971). Los Angeles: The Architecture of Four Ecologies. New York: Harper and Row.

Barata Salgueiro, T. (2001). Lisboa, Periferia e Centralidades [Lisbon: Periphery and Centralities]. Oeiras: Celta.

Barbieri, P. (Ed.). (2006). Infraspazi [Infraspaces]. Roma: Meltemi.

Barreiros, J. J. (1988). Auto-estrada Lisboa-Cascais. Um atribulado processo de intervenção sócio-urbanística [Lisbon-Cascais Highway: a difficult process of socio-urbanistic intervention]. Sociedade e Território, 7, 35-47.

Berger, A. (2006). Drosscape - Wasting Land in Urban América. New York: Princeton Architectural Press.

Brito, J. B., \& Rollo, M. F. (1996). Indústria/Industrialização [Industry/Industrialization]. In F. Rosas \& J. B. Brito (Coords.), Dicionário de História do Estado Novo [Dictionary of History of Estado Novo] (pp. 460-480). Lisboa: Círculo de Leitores.

Brito-Henriques, E. (2017). Arruinamento e regeneração do espaço edificado na metrópole do século XXI: o caso de Lisboa [Ruination and built environment regeneration in the 21 st-century metropolis: the case of Lisbon]. EURE: Revista Latinoamericana de Estudios Urbano Regionales, 43(128), 251-272.

Brons, R. (2010). Designing the New Dutch Waterline. In N. Meijsmans (Ed.), Designing for a Region (pp. 168-177). Amsterdam: Sun Architecture.

Bruttomesso, R. (2001). Complexity on the urban waterfront. In R. Marshall (Ed.), Waterfronts in Post-Industrial Cities (pp. 39-49). London/New York: Spon.

Cabral, J., \& Rato, B. (2003). Urban development for competitiveness and cohesion: The Expo 98 urban project in Lisbon. In F. Moulaert, A. Rodriguez \& E. Swyngedouw (Eds.), The Globalized City: Economic Restructuring and Social Polarization in European Cities (pp. 209-228). Oxford, UK: Oxford University Press.

Caetano, M. (2008). O Planeamento Regional em Portugal no Período do III Plano de Fomento [Regional Planning in Portugal during time of the $3 \mathrm{rd}$ Development Plan]. Lisboa: Departamento de Prospectiva e Planeamento e Relações Internacionais.

Cavaco, C. (2009). Formas de habitat suburbano: tipologias e modelos na área metropolitana de Lisboa [Forms of suburban habitat: typologies and models in the Lisbon metropolitan área]. (Tese de Doutoramento). Retrieved from https://www. repository.utl.pt/handle/10400.5/3652

Choay, F. (1994). Le règne de l'urbain et la mort de la ville [The reign of the urban or the death of the town]. In J. Dethier \& A. Guiheux (Dirs.), La Ville. Art et architecture en Europe (1870-1993) [The City. Art and architecture (1870-1993)] (pp. 26-35). Paris: Centre Georges Pompidou.

Câmara Municipal de Lisboa. (CML). (1967). Plano Director da Cidade de Lisboa [Lisbon Master Plan]. Lisboa: CML.

Corbin, C. (2003). Vacancy and the Landscape: Cultural Context and Design Response. Landscape Journal, 22(1), 12-24.

Corboz, A. (1983). Le territoire comme palimpseste [The territory as a palimpsest]. Diogène, 121, 14-35.

Costa, J. P. (2006). La ribera entre proyectos: formación y transformación del territorio portuario, a partir del caso de Lisboa [The riverfront between projects: formation and transformation of the port 
territory, with Lisbon as a case]. (Tese de Doutoramento). Retrieved from http://www.tesisenred.net/handle/10803/6960

Costa, M., \& Vital, R. (2005). Evolução Histórica dos Sistemas de Abastecimento de Água a Lisboa [Historical evolution of water supply systems in Lisbon]. In Grundfos (Ed.), Manual de Engenharia de Sistemas de Pressurização [Manual of Pressurization Systems Engineering] (pp. 7-29). Lisboa: Bombas Grundfos Portugal.

Coutard, O. (2010). Services urbains: la fin des grands réseaux? [Urban services: the end of large scale networks?]. In O. Coutard \& J. P. Lévy (Dirs.), Écologies urbaines [Urban Ecologies] (pp. 102-129). Paris: Ed. Economica-Anthropos.

Cruz, M. A. (1973). A margem sul do estuário do Tejo: factores e formas de organização do espaço [The south bank of Tagus estuary: factors and forms of spatial organization]. Lisboa: Faculdade de Letras, Universidade de Lisboa.

Custódio, J. (2005). A indústria portuguesa na época do Movimento Moderno, 1925-1965 [The portuguese industry in the Modern Movement period, 1925-1965]. In C. G. Braña, S. Landrove \& A. Tostões (Eds.), A Arquitectura da Indústria, 1925-1965 [The Architecture of Industry, 1925-1965] (pp. 14-35). Barcelona: Fundação DOCOMOMO Ibérico.

Custódio, J. (1994a). As infraestruturas: os canais de Lisboa [The infrastructures: the channels of Lisbon]. In AA.VV. (Ed.), Lisboa em Movimento: 1850-1920 - a modernização da cidade entre 1850 e 1920. Da Regeneração à Grande Guerra, a transformação do urbanismo, das infraestruturas, dos transportes e serviços, dos espaços sociais e públicos [Lisbon in Movement: 1850-1920 - the modernization of the city between 1850 and 1920. From Regeneration to the Great War, the changes in Urbanism, infrastructures, transports and services, and of social and public spaces] (pp. 93-131). Lisboa: Livros Horizonte.

Custódio, J. (1994b). Reflexos da industrialização na fisionomia e vida da cidade [Impacts of industrialization in the city's physionomy and life]. In I. Moita (Coord.), O Livro de Lisboa [The Book of Lisbon] (pp. 435-492). Lisboa: Livros Horizonte. Delbere, D. (2010). La fabrique de l'espace public - Ville, paysage et démocratie [The making of public space - City, landscape and democracy]. Paris: Ellipses Édition Marketing.
Delalex, G. (2007). Le temps synchronique des infrastructures [The synchronic time of infrastructure]. In C. Prelorenzo \& D. Rouillard (Dirs.), Le temps des infrastructures [The time of infrastructures] (pp. 33-40). Paris: L'Harmattan.

Dematteis, G. (1995). Progetto implicito. Il contributo della geografia umana alle scienze del territorio [Implicit project: The contribution of human geography to the territorial science]. Milano: Franco Angeli.

Desimini, J. (2013). Blue voids: stormwater strategies for abandoned lands. Journal of Landscape Architecture, 8(2), 64-73.

Desportes, M. (2005). Paysages en mouvement - Transports et perception de l'espace - XVIIIe-XXe Siècle [Landscapes in mouvement - Transports and spatial perception - 18th-20th century]. Paris: Gallimard.

Disco, C. (2008). Taming the Rhine: Economic Connection and Urban Competition. In M. Hard \& T. Misa (Eds.), Urban Machinery. Inside Modern European Cities (pp. 23-48). Cambridge/London: The MIT Press.

Donini, G. (2008). Margini della mobilità [The margins of mobility]. Col. Babele, Roma: Meltemi Editore.

Easterling, K. (1999). Organization space: landscapes, highways and houses in America. Cambridge: MIT Press.

Escária, S., \& Ribeiro, J. F. (2010). As Formas e o Funcionamento das Cidades e os Desafios da Sustentabilidade [The forms and the functioning of cities and the challenges of sustainability]. Lisboa: Departamento de Prospectiva e Planeamento.

Farhat, G. (2011). Infrastructural Landscape: Beyond memory and Metaphor. In T. Hauck, R. Keller \& V. Kleinekort (Eds.), Infrastructural Urbanism. Addressing the In-between (pp. 273-288). Berlin: DOM Publishers.

Font, A. (Coord.). (2004). L'explosión de la ciudad: transformaciones territoriales en las regiones urbanas de la Europa Meridional, Barcelona [The explosion of the city: territorial transformations in the Southern European urban regions]. Catalunya: Collegi d'Arquitectes de Catalunya-COAC/Forum Universal de les Cultures.

Font, A. (1997). Anatomia de una metrópoli discontinua: la Barcelona Metropolitana [Anatomy of a discontinuous metropolis: the Metropolitan Barcelona]. Papers, 26, 9-19. 
Gandy, M. (2013). Marginalia: Aesthetics, ecology, and urban wastelands. Annals of the Association of American Geographers, 103(6), 1301-1316.

Gomes, G. (2005). O Gabinete de Estudos e Planeamento de Transportes Terrestres 1961-1971 [The Office of Land Transport Studies and Planning 1961-1971]. In L. G. Lobato (Coord.), A Concepção da Rede Ferroviária no Sistema Global de Transportes - O Gabinete de Estudos e Planeamento de Transportes Terrestres [The inception of the railraod network in the global transportation system - The Office of Land Transport Studies and Planning] (pp. 87-106). Vol. 4, Lisboa: CP/DGTTF.

Gabinete do Plano Director da Região de Lisboa. (GPDRL). (1964). Plano Director da Região de Lisboa. Anteplano [Regional Master Plan of Lisbon - preliminary plan]. Lisboa: Gabinete do Plano Director da Região de Lisboa.

Graham, S., \& Marvin, S. (2001). Splintering Urbanism. Networked infrastructures, technological mobilities and the urban condition. London/New York: Routledge.

Herce Vallejo, M., Magrinyà, F., \& Miró, J. (2004). Construcció de ciutat i xarxas d'infrastructures [City building and infrastructural networks]. Barcelona: Universidad Poltécnica de Catalunya.

IBA Fürst-Pückler-Land (Ed.). (2010). New Landscape Lusatia - Catalogue 2010. Berlin: Jovis.

Kullmann, K. (2011). Thin parks/thick edges: towards a linear park typology for (post)infrastructural sites. Journal of Landscape Architecture, 6(2), 70-81.

Lefebvre, V. (2007). La question de l'obsolescence des infrastructures [The issue of infrastructural obsolescence]. In C. Prelorenzo \& D. Rouillard (Dirs.), Le temps des infrastructures [The time of infrastructures] (pp. 113-122). Paris: L'Harmattan.

Llop, C. (1997). Lògiques i espais projectuals d'una metròpoli, Barcelona 1976-1992 [Logics and project spaces of a metropolis, Barcelona 1976-1992]. Papers, 26, 37-52.

Lobo, F. S. (2015). A Defesa de Lisboa. Linhas de Torres Vedras, Lisboa, Oeiras e Sul do Tejo (1809-1814) [The defense of Lisbon. The Lines of Torres Vedras, Lisbon, Oeiras and the South of Tagus]. Cascais: Tribuna da História.

Lokman, K. (2017). Vacancy as a laboratory: design criteria for reimagining social-ecological systems on vacant urban lands. Landscape Research, 42(7), 728-746.
Mangin, D. (2013). Paris/Babel. Une mégapole européenne [Paris/Babel . An european megalopolis]. Paris: La Villette.

Mangin, D. (2004). La ville franchisé: Formes et structures de la ville contemporaine [The franchised city: Forms and structures of the contemporary city]. Paris: La Villette.

Marinoni, G. (2006). Infrastrutture nel progetto urbano [Infrastructure in the urban project]. Milano: Franco Angeli

Martins, J. P., Brion, M., Sousa, M., Levy, M., \& Amorim, Ó. (1996). O Caminho de Ferro Revisitado: O Caminho de Ferro em Portugal de 1856 a 1996 [Revisiting the Railroad. The railroad in Portugal from 1856 to 1996]. s.l.: Caminhos de Ferro Portugueses.

Matias Ferreira, V. (1986). A cidade de Lisboa: de capital do império a centro da metrópole [The city of Lisbon: from capital of the empire to centre of the metropolis]. (Tese de Doutoramento). Lisboa: ISCTE-IUL.

Matias Ferreira, V., Indovina, F. (1999). A cidade da Expo'98 [The city of Expo'98]. Lisboa: Bizâncio.

Matos, A. C. (2009). Gas industry and urban modernisation: Lisbon in the 19th and 20th centuries. Transportes, Servicios y Telecomunicaciones, 16, 62-80.

Matos, A. C. (2004). A electricidade em Portugal: dos primórdios à $2^{a}$ Guerra Mundial [The electricity in Portugal: from its inception to the World War II]. Lisboa: EDP.

Mossop, E. (2006). Landscape of infrastructure. In C. Waldheim (Ed.), The Landscape Urbanism Reader (pp. 163-177). New York: Princeton Architectural Press.

Murteira, M. H. (1999). A nova linha de fortificação e a delimitação do perímetro da cidade [The new line of fortification and the laying of the city perimeter]. In M. H. Murteira (Ed.), Lisboa das Restauração às Luzes: uma análise da evolução urbana [Lisbon from the Restauration to the Lights: an analysis of urban evolution] (pp. 123-149). Lisboa: Editorial Presença.

Neuman, M., \& Smith, S. (2010). City Planning and Infrastructure: Once and Future Partners. Journal of Planning History, 9(1), 21-42.

Nunes, J. P. (2011). Florestas de Cimento Armado. Os Grandes Conjuntos Residenciais e a Constituição da Metrópole - Lisboa, 1955-1981 [Forests made 
of reinforced concrete: Large residential developments and the constitution of the Metropolis of Lisbon (1955-2005)]. Lisboa: Fundação Calouste Gulbenkian.

Offner, J. M. (1996). «Réseaux» et «Large Technical System»: concepts complémentaires ou concurrents? ['Networks' and 'Large Technical Systems' : complementary or competing concepts]. Flux Cahiers scientifiques internationaux Réseaux et Territoires, 26, 17-30.

Oswald, F., \& Baccini, P. (2003). Netzstad: Designing the urban. Basel: Birkäuser.

Pavia, R. (2002). Babele. La città della dispersione [Babel. The city of dispersion]. Roma: Meltemi editore.

Pavia, R. (1996). Le paure dellurbanistica. Disagio e incertezzaa nel progetto della città contemporânea [The fear of urbanism. Desire and uncertainty in the project of the contemporary city]. Genova: Costa \& Nolan.

Panerai, P. (2008). Paris Métropole. Formes et échelles du Grand-Paris [Paris Metropolis. Forms and scales of the Great-Paris]. Paris: Éditions de La Villette.

Pinheiro, M. (1994). Lisboa e a rede ferroviária [Lisbon and railroad network]. Ler História, 26, 77-91.

Pinheiro, M., Baptista, L. V., \& Vaz, M. J. (2001). Cidade e metrópole: centralidades e marginalidades [City and metropolis: centralities and marginalities]. Lisboa: Celta.

Portas, N., Domingues, Á., \& Cabral, J. (2003). Políticas Urbanas. Tendências, estratégias e oportunidades [Urban policies. Trends, strategies and opportunities]. Lisboa: Fundação Calouste Gulbenkian.

Portas, N., Domingues, Á., \& Cabral, J. (2011). Políticas Urbanas II. Transformações, regulações e projectos [Urban policies II. Transformations, regulation and projects]. Lisboa: Fundação Calouste Gulbenkian.

Regionalverband, R. (2010). Unter freiem Himmel Emscher Landschaftspark [Under the Open Sky - Emscher Landscape Park]. Basel: Birkhauser.

Roberts, P., \& Sykes, H. (2000). Urban Regeneration: A Handbook. London: SAGE.

Rodrigues, J. (1999). A expansão programada de Lisboa para a margem sul: Almada, 1938-1950 [The programmed expansion of Lisbon the the south bank: Almada, 1938-1950] (Dissertação de Mestrado). Lisboa: ISCTE-IUL.

Rollo, M. F., \& Brito, J. B. (1996). Ferreira Dias e a constituição da Companhia Nacional de Electrici- dade [Ferreira Dias and the constitution of the National Electrical Company]. Análise Social, 31(136-137), 343-354.

Rouillard, D. (2007). «La ville à dix minutes». La distance de temps dans la théorie de la ville mesurée ['The city in ten minutes'. The distance of time in the measured city theory]. In C. Prelorenzo \& D. Rouillard (Dirs.), Le temps des infrastructures [The time of infrastructures] (pp. 11-22). Paris: L'Harmattan.

Santana, E., \& Sucena, F. (Dirs.). (1994). Dicionário da história de Lisboa [Dictionary of the history of Lisbon]. Lisboa: Carlos Quintas \& Associados.

Santos, J. R. (2017). Discrete landscapes in metropolitan Lisbon: open space as a planning resource in times of latency. Planning Practice \& Research, $32(1), 4-28$.

Santos, J. R. (2013). Planning a metropolis from infrastructure: Lisbon from 1940 to 1966. Journal of Planning History, 12(4), 311-332.

Santos, J. R. (2012). Espaços de mediação infraestrutural: Interpretação e projecto na produção do urbano no território metropolitano de Lisboa [Spaces of infrastructural mediation: interpretation and project in the production of the urban in the metropolitan territory of Lisbon]. (Tese de Doutoramento). Retrieved from https://www.repository.utl.pt/handle/10400.5/5429

Schulz-Dornburg, J. (2012). Ruinas modernas, una topografía de lucro [Modern ruins, a topography of profit]. Barcelona: Ambit Serveis Editorials.

Secchi, B. (2005). La città nel ventesimo secolo [The city in the 20th century]. Roma: Laterza.

Sieverts, T. (2003[1997]). Cities without Cities: Between Place and World, Space and Time, Town and Country. London, New York: Spon Press/Routledge.

Silva, J. M. L., Gomes, G., \& Cruz, I. (2004). Sobre o complexo industrial da CUF no Barreiro [On the industrial complex of CUF in Barreiro]. In M. Heitor, J. M. B. Brito \& M. F. Rollo (Coords.), Momentos de inovação e engenharia em Portugal no século XX [Moments of innovation and engineering in Portugal in the 20th century] (pp. 243-290). Vol. 3, Lisboa: Dom Quixote.

Silva, R. H. (Dir.). (1989). Lisboa de Frederico Ressano Garcia, 1874-1909 [Lisbon of Frederico Ressano Garcia, 1874-1909]. Lisboa: Câmara Municipal de Lisboa. 
Smets, M. (2004). Le paysage contemporain des infrastructures. Le paradox de l'intégration [The contemporary landscape of infrastructures. The paradox of integration]. In S. Allemand, F. Ascher \& J. Lévy (Dirs.), Les sens du movement [The meanings of movement] (pp. 249-256). Paris: Éditions Belin.

Shannon, K., \& Smets, M. (2010). The Landscape of Contemporary Infrastructure. Rotterdam: NAi Publishers.

Solà-Morales, M. (2004[1996]). Contra el modelo de metrópolis universal [Against the model of universal metropolis]. In A. Martín Ramos (Ed.), Lo urbano en 20 autores contemporâneos [The urban in 20 contemporary authors] (pp. 99-104). Barcelona: Edicions UPC.

Solà-Morales, I. (1995). Terrain vague. In C. C. Davidson (Ed.), Anyplace (pp. 188-123). Cambridge, MA: MIT Press.

Tölle, A. (2009), Infrastructures et grands projets urbains à Lyon, Hambourg et Gdansk: Une aproche des conditions spécifiques d'une metrópole d'Europe centro-orientale [Infrastructures and large urban projects in Lyon, Hamburg and Gdansk: an approach to specific conditions of a European central-eastern metropolis]. In C. Prelorenzo \& D. Rouillart (Eds.), La métropole des infrastructures [The metropolis of infrastructures] (pp. 234-247). Paris: Éditions A. et J. Picard.
Veiga da Cunha, L. (1948). As águas de Lisboa [The waters of Lisbon]. Revista da Ordem dos Engenheiros, 54, 283-307.

Veltz, P. (2004). Léconomie de touts les mobilités [The economy of all mobilities]. In S. Allemand, F. Ascher \& J. Lévy (Dirs.), Les sens du movement [The meanings of mouvement] (pp. 49-59). Paris: Éditions Belin.

Verschuure-Stuip, G. A. (2014). Project New Dutch Waterline and Project Arcadian Landscapes Guidelines for new spatial development based on heritage. AESOP Conference 2014, Delft.

Vieira da Silva, A. (1940). O Termo de Lisboa [The territory of Lisbon]. Lisboa: Publicações culturais da Câmara Municipal de Lisboa.

Vormann, B. (2015). Toward an infrastructural critique of urban change: Obsolescence and changing perceptions of New York City's waterfront. City, 19(2-3), 356-364.

Wall, E. (2011). Infrastructural Form, Interstitial Spaces and Informal Acts. In T. Hauck, R. Keller \& V. Kleinekort (Eds.), Infrastructural Urbanism. Addressing the In-between (pp. 145-158). Berlin: DOM Publishers.

Urry, J. (2004). Petits mondes [Small worlds]. In S. Allemand, F. Ascher \& J. Lévy (Dirs.), Les sens du movement [The meanings of movement] (pp. 37-48). Paris: Éditions Belin. 